\title{
AVALIAÇÃO DO CRONOGRAMA DE PAGAMENTO DE UMA SEGURADORA ESPECIALIZADA EM SAÚDE ${ }^{1}$
}

\author{
EVALUATION OF THE PAYMENT SCHEDULE \\ OF A HEALTH INSURER
}

\section{Mara Jane Contrera Malacrida ${ }^{2}$}

Doutora em Controladoria e Contabilidade pela Universidade de São Paulo Professora do Departamento de Contabilidade e Atuária da USP

maracontrera@uol.com.br

orcid.org/0000-0002-1157-6799

\section{Letícia Fajardo}

Titulação e onde obteve a titulação

Instituição em que trabalha

lele.fajardo@gmail.com

orcid.org/0000-0001-9281-6928

\section{Gerlando Augusto Sampaio Franco de Lima}

Doutor em Controladoria e Contabilidade pela Universidade de São Paulo

Professor do Departamento de Contabilidade da Universidade de Illinois

gerlandolima@gmail.com

orcid.org/0000-0002-2414-2543

\author{
Eduardo Flores \\ Doutor em Controladoria e Contabilidade pela Universidade de São Paulo \\ Pós-Doutorando em Finanças pela EASP-FGV e em Contabilidade pela FEA/USP \\ eduardoflores@usp.br \\ orcid.org/0000-0002-5284-5107
}

\section{RESUMO}

Objetivo: O presente estudo objetivou desenvolver um modelo para estimação dos pagamentos mensais de sinistros que envolveram a colaboração de prestadores de serviços de operadoras de planos de saúde.

Fundamento: Embora cada seguradora possua um cronograma de pagamentos específico, é factível conceber que a data da quitação é dependente do momento em que a ocorrência é recebida pela

\footnotetext{
1 Artigo recebido em: 24/04/2017. Revisado por pares em: 11/05/2017. Reformulado em: 23/07/2017. Recomendado para publicação em: 25/08/2017 por Luiz Felipe de Araújo Pontes Girão (Editor Geral). Publicado em: 02/09/2017. Organização responsável pelo periódico: UFPB.

2 Endereço: Av. Prof. Luciano Gualberto, 908 - Butantã.

DOI: http://dx.doi.org/10.18405/recfin20180103
} 
seguradora. No entanto, destaca-se que a variação dos sinistros pagos em cada mês decorre de distintos fatores, sendo a sazonalidade do uso das coberturas oferecidas por essas empresas muito relevante para inserção em um modelo de pagamentos.

Método: Por meio da análise da sazonalidade de períodos anteriores, foi concebido um modelo de pagamentos de sinistros mensais por meio de uma de uma simulação de eventos.

Resultados: No âmbito dos resultados verificou-se que o modelo proposto demonstrou uma expressiva aderência para 7 dos 10 meses analisados. Isto é, comparando-se os valores estimados a partir do modelo com os valores reais, verificou-se que para 7 meses o erro, em módulo, foi inferior a $10 \%$. Contribuições: $O$ modelo ora apresentado possui condições de ser utilizado para estimar o fluxo de pagamentos futuros, possibilitando o incremento de procedimentos de gestão de recursos financeiros das operadoras de planos de saúde, bem como, uma melhora nos seus resultados financeiros. Ressalta-se que outros parâmetros, como, por exemplo, o perfil das carteiras das seguradoras e a região, poderão ser incorporados a versões futuras desse modelo de modo a incrementar sua acurácia.

Palavras-chave: seguradora, planos de saúde, administração financeira, sazonalidade, sinistro.

\section{ABSTRACT}

Objective: The present study aimed to develop a model for estimating monthly claims payments that involved the collaboration of service providers of health plan operators.

Rationale: Although each insurer has a specific payment schedule, it is feasible to conceive that the date of discharge is dependent upon the time the event is received by the insurer. However, it should be noted that the variation of the claims paid in each month is due to different factors, and the seasonality of the coverage offered by these companies is very relevant for insertion into a payment model.

Method: Through the analysis of the seasonality of previous periods, a model of payments of monthly claims was conceived through one of an event simulation.

Results: In the scope of the results it was verified that the proposed model showed a significant adhesion for 7 of the 10 months analyzed. That is, by comparing the estimated values from the model with the actual values, it was verified that for 7 months the error, in module, was less than $10 \%$.

Contributions: The model presented here has conditions to be used to estimate the flow of future payments, making it possible to increase the procedures for managing the financial resources of the health plan operators, as well as an improvement in their financial results. It should be noted that other parameters, such as the profile of insurance portfolios and the region, could be incorporated into future versions of this model in order to increase its accuracy.

Keywords: Insurer, health plans, financial management, seasonality, claim.

\section{INTRODUÇÃO}

A Demonstração dos Fluxos de Caixa é uma demonstração de apresentação obrigatória pelas sociedades de capital aberto ou que tenham patrimônio líquido superior a dois milhões de reais (Lei 11.638/2007). De acordo com o critério estabelecido, a Demonstração do Fluxo de Caixa (DFC) deve conter os fluxos de caixa das atividades operacionais, das atividades de investimento e das atividades de financiamento de uma empresa. No entanto, cada empresa tem sua especificidade, ou seja, fluxos monetários de entradas e saídas diferentes, o que torna indispensável o conhecimento do ciclo financeiro da empresa para que a gestão financeira seja eficiente.

Entretanto, a DFC requerida normativamente tem por finalidade conciliar as variações de caixa de um período para o outro vis-à-vis as transações econômico-financeiras praticadas por uma 
companhia. De acordo com Martins et al. (2013) o propósito fundamental da DFC é prover informações sobre os pagamentos e recebimentos, em dinheiro, de uma empresa, auxiliando os usuários das demonstrações contábeis na análise da capacidade da empresa de gerar e consumir caixa e equivalentes de caixa.

Logo, sem prejuízos de outras leituras, é possível inferir que a DFC tem um caráter retrospectivo, muito embora suas informações sejam utilizadas para eventuais tomadas de decisões por parte dos alocadores de recursos econômicos.

Em virtude dessa perspectiva temporal, é costumeiro que se utilize no âmbito da gestão das companhias, modelos de fluxo de caixa desenvolvidos com bases em informações prospectivas. Segundo Assaf Neto e Silva (2002), a gestão preditiva do fluxo de caixa é impreterível a fim de que as organizações possam ter uma sinalização do seu rumo financeiro, pois a insuficiência de caixa pode, tomada no limite, levar uma empresa a descontinuidade de suas operações.

De acordo com Frezzati (2006) a gestão do fluxo de caixa diário pode ser realizada tomandose o enfoque tático, o qual está voltado ao restrito acompanhamento do fluxo de caixa, ou pode ser realizada por meio da abordagem estratégica, a qual envolve o volume de transações tanto no curto, quanto no longo prazo.

No âmbito das companhias seguradoras a gestão do fluxo de caixa é revestida por complexidades adicionais provenientes de características particulares desse segmento, como, por exemplo, a necessidade da manutenção de ativos garantidores dos riscos assumidos por meio das apólices emitidas. Knyazeva et al. (2016) destaca que as companhias de seguros oferecem um tipo especial de serviços e para cumprir com suas obrigações formam reservas que devem ser respectivamente protegidas por meio de ativos financeiros de alta liquidez.

No tocante às operadoras de planos de saúde, Campello (2005) ressalta que operadoras de planos de saúde recebem prêmios em virtude do fornecimento de coberturas acerca de benefícios e/ou sinistros que impactem seus beneficiários. Dessa forma, o autor ressalta que diferentes fatores como prêmios insuficientes, cálculos incorretos de provisões técnicas, alterações na frequência de sinistros, dentre outros, podem afetar veementemente tais companhias, impondo-lhes riscos de solvência em uma problemática mais avançada. Sendo assim a boa gestão, portanto preditiva, do fluxo de caixa de uma empresa do ramo de seguros privados é caraterística essencial para sua continuidade (Westenberger, 1995, Salles \& Santos, 2004, Campello, 2005).

Nesse contexto, é concebível assumir a premissa de que uma das principais entradas e saídas de caixa relacionadas às atividades operacionais das seguradoras decorra do recebimento de prêmios e do pagamento de sinistros. Via de regra os sinistros pagos pelas operadoras são destinados aos prestadores de serviços previamente castrados em sua rede de colaboradores.

A partir do momento em que uma operadora de planos de saúde firma um contrato com um prestador de serviços médicos e hospitalares as duas partes realizam acordos de valores a serem pagos pelas operadoras aos prestadores de acordo com cada serviço, bem como os meios do envio das contas, definição de procedimentos com necessidade de autorização prévia para realização, métodos de certificação de validade dos planos de saúde do paciente, entre outros. Destes, o acordo importante para esse estudo é a definição de um cronograma de pagamento das contas para os prestadores. A partir desse cronograma é definido o período de aviso do sinistro e o seu respectivo pagamento para os seus prestadores referenciados/credenciados.

Nesse sentido, o objetivo do presente estudo centra-se no desenvolvimento de um modelo de estimativa de pagamentos mensais aplicado a operadoras de planos de saúde para os prestadores de sua rede, visando a antecipação da ciência de tais dispêndios financeiros com o intuito de se incrementar a gestão financeira de tais organizações.

A estimativa dos valores a serem pagos mensalmente requer uma análise minuciosa do fluxo de entradas e saídas ocorridas, uma vez que há uma potencial variação significativa nos valores dos 
desembolsos mensais, a qual está muito provavelmente correlacionada a diferentes fatores como a variação de vidas na carteira de beneficiários das operadoras, que influencia o montante de sinistros a ser pago, e os efeitos sazonais da ocorrência desses eventos.

Adicionalmente ao modelo de previsão dos sinistros, a gestão financeira da empresa seria melhor se os pagamentos fossem constantes no decorrer do ano, de forma a alocar melhor os prêmios recebidos, uma vez que o prêmio não sofre tais alterações sazonais, apenas são reajustados anualmente. Em função dessas alterações há meses com superávit e meses com déficit para a operadora. Nesse sentido, a gestão das entradas e saídas de recursos monetários provenientes da atividade operacional contribuiria tanto para a melhora da capacidade de honrar os compromissos assumidos nos prazos contratados quanto para um melhor resultado operacional, uma vez que seria possível reduzir os custos financeiros relacionados à manutenção de recursos disponíveis em excesso.

Para o desenvolvimento do modelo de previsão de Sinistro pago por uma seguradora utilizou-se a base de dados de uma seguradora tradicional no mercado, contendo a data de execução do procedimento, a data de recebimento da conta, a data de pagamento efetivo da conta, o valor da conta e quantidade de vidas da carteira nos anos de 2011, 2012 e 2013.

As análises evidenciaram que o Modelo desenvolvido apresentou uma boa aderência para 7 dos 10 meses analisados. Comparando os valores estimados a partir do Modelo com os valores reais, verifica-se que para 7 meses o erro, em módulo, foi inferior a 10\%. Nas próximas sessões serão apresentados a Fundamentação Teórica, a Metodologia, o desenvolvimento do Modelo, além dos resultados e conclusões.

\section{FUNDAMENTAÇÃO TEÓRICA}

\subsection{O Funcionamento de uma Seguradora}

A Resolução Normativa n 363 da Agência Nacional de Saúde Suplementar (ANS) estabelece os requisitos para celebração dos contratos escritos firmados entre as operadoras de planos de assistência à saúde e os prestadores de serviços de atenção à saúde. O artigo $4^{\circ}$ desta Resolução estabelece que:

os contratos escritos devem estabelecer com clareza as condições para a sua execução, expressas em cláusulas que definam os direitos, obrigações e responsabilidades das partes, incluídas, obrigatoriamente, as que determinem: I - o objeto e a natureza do contrato, com descrição de todos os serviços contratados;

II - a definição dos valores dos serviços contratados, dos critérios, da forma e da periodicidade do seu reajuste e dos prazos e procedimentos para faturamento e pagamento dos serviços prestados; (...)

Dessa forma, é de responsabilidade das partes definir como serão realizados os pagamentos dos sinistros ocorridos. Basicamente o "trajeto percorrido" por um sinistro em qualquer operadora está descrito no esquema da Figura 1.

Podemos dar um exemplo valendo-se do cronograma de pagamento de uma seguradora ${ }^{3}$ em que:

Os faturamentos enviados (...) até o dia 20 (vinte) de cada mês terão seu crédito no dia 15 (quinze) do mês subsequente, e aqueles enviados até o dia 05 (cinco), terão seu crédito no último dia útil do mesmo mês.

\footnotetext{
${ }^{3}$ Dados obtidos no "Manual de Orientações Técnicas e Administrativas ao Referenciado" da seguradora TEMPO Saúde.
} 
Figura 1: Esquema de processo de pagamento de sinistro.

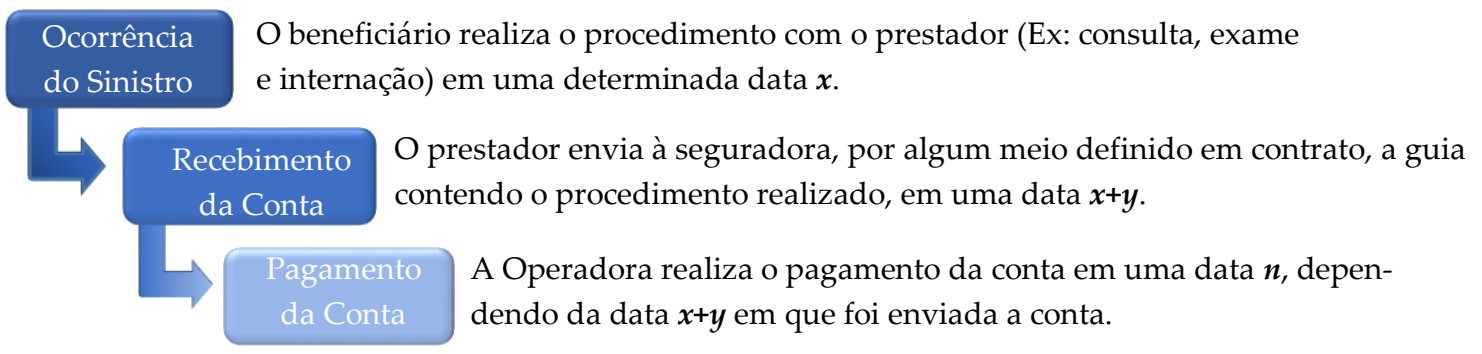

Fonte: Adaptado da Resolução Normativa nº 363

Isso significa que a seguradora possui duas datas $n$ de pagamento de contas a prestadores, uma no dia 15 e outra no último dia útil do mês. Enquanto o pagamento das contas nas datas especificadas é de obrigação da seguradora, o envio das contas é de responsabilidade do prestador e o intervalo entre a ocorrência do sinistro e do envio também.

Verifica-se nesse caso que há sempre um intervalo mínimo de 25 dias corridos entre a data de recebimento das contas e a data de pagamento. Esse intervalo, que pode variar entre as diferentes operadoras, acontece em toda e qualquer operadora e tem como motivação a necessidade de um período de análise de contas (identificação de fraudes, cobranças de valores indevidos, etc.), além do tempo imprescindível para a organização cadastral (cadastro dos sinistros em banco de dados, por exemplo) e financeira (agendamento dos pagamentos) da empresa.

No caso de um sinistro ocorrido em 29 de maio (data $x$ ), partindo do pressuposto de que se trata de um exame realizado em uma clínica muito bem organizada que envia as contas no prazo de até 3 dias úteis após a execução, a conta será enviada no dia 2 de junho (data $x+y$ ). Como a conta está sendo recebida após o dia 20 do mês e anterior ao dia 5 do mês seguinte, a mesma será, portanto, paga no dia 30 de junho (último dia útil do mês seguinte, data $\boldsymbol{n}$ ). Se ocorresse, por exemplo de a clínica ter um problema com funcionários que enviam as contas, e o sinistro fosse enviado apenas no dia 06 de junho, ela só seria quitada no dia 15 de julho (nova data $n$, determinada pela data de recebimento da conta). Dessa maneira, percebe-se que podem existir contas da competência de maio pagas tanto no mês de junho, como julho ou até mesmo em meses subsequentes.

Para ajustar o valor que será pago no mês de junho, por exemplo, para o caso de ser um período de sinistro mais alto do que a média, poderia (claro que em acordo com os prestadores), diminuir o período de recebimento das contas que serão pagas em 30 de junho: ao invés de o envio ser até 5 de junho para que as contas sejam pagas nesse dia, poderia determinar que, para o pagamento ser efetuado em 30 de junho, as contas deveriam ser enviadas até o dia 2 de junho, por exemplo, o que reduziria o número de contas recebidas e, consequentemente, o valor que seria pago em junho. No entanto, o valor do mês seguinte sofreria um aumento referente a esses dias de recebimento transferidos para o mês consecutivo.

Todavia, para realizar esses ajustes é preciso avaliar quais meses deveriam ser adaptados para um período maior ou menor de recebimento de contas, conhecimento esse diretamente ligado à sazonalidade, que é a principal influência para as variações dos valores pagos nos meses.

\subsection{Sazonalidade}

Sazonal por definição do dicionário Melhoramentos é "adj. 1. Relativo à estação do ano; 2. Que se verifica ou ocorre a cada estação". Exemplificando, as vendas de passagens aéreas para a região nordeste possuem um efeito sazonal de acordo com a estação do ano, dado que no verão a procura por esse tipo de viagem é muito maior. Por conseguinte, podemos dizer que a Sazonalidade para vendas de passagens aéreas para o Nordeste é maior no verão, e menor no inverno. 
Entretanto, a sazonalidade não está relacionada apenas à determinadas épocas do ano. Pode-se dizer, por exemplo, que em uma casa existe uma maior sazonalidade para o pagamento de contas nos dias $1^{\circ}, 15$ e 30 de cada mês (já que são muitas vezes os dias de recebimento dos salários).

Analisando os dados do SUS a seguir, pode-se verificar na Figura 2 os padrões de sazonalidade encontrados para cada mês dentro do ano.

Figura 2. Atendimentos Ambulatoriais do SUS no Brasil, de 2010 a 2013.

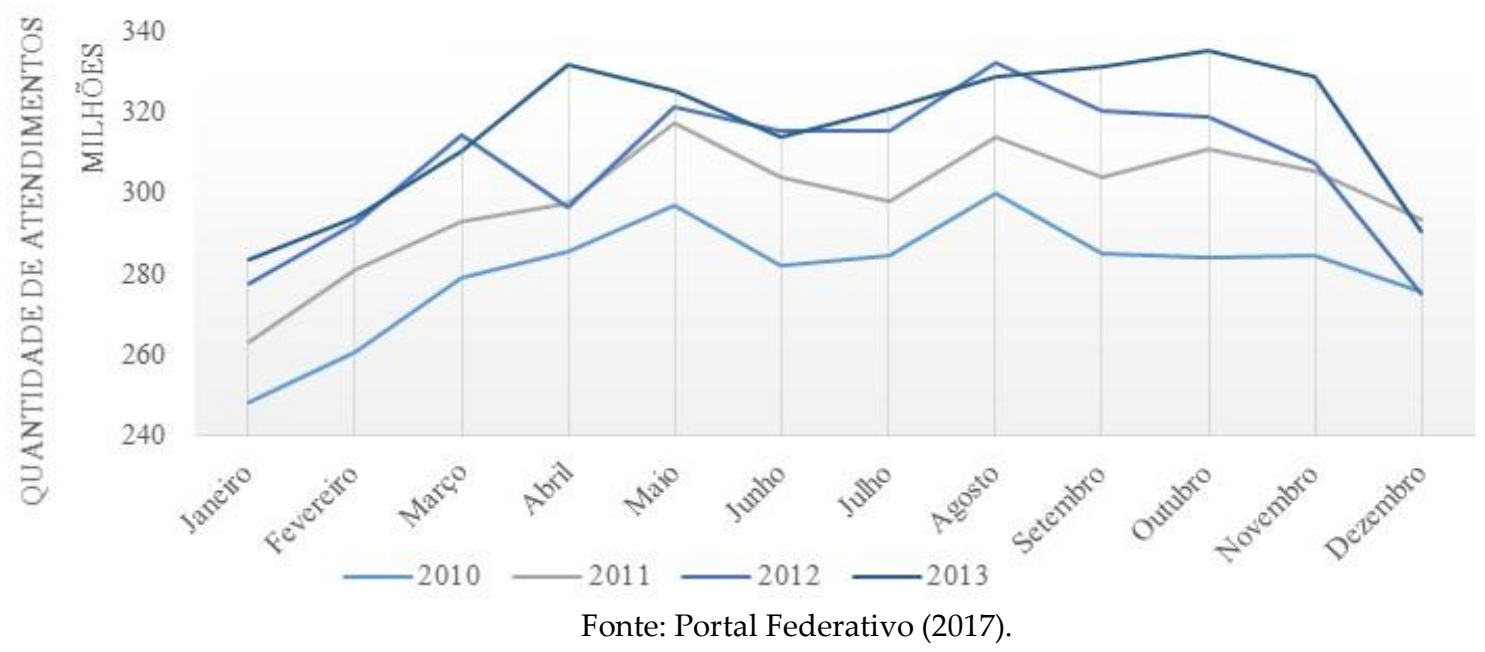

Conforme pode-se verificar na Figura 2, que apresenta o número de atendimentos ambulatoriais $^{4}$ do SUS, existem alguns meses com comportamento semelhante no decorrer dos anos, enquanto outros possuem uma certa variação. As variações podem ser explicadas por fatores como epidemias ou simplesmente por uma mudança no padrão de utilização dos serviços de saúde durante esses meses.

Por exemplo, para o mês de abril de 2012 e 2013, verifica-se que, no primeiro houve uma queda brusca na frequência de utilização, enquanto no segundo houve um forte agravo, ambas as situações, fora do padrão dos anos de 2010 e 2011.

Para outros meses, no entanto, existe um padrão bem definido, como janeiro, fevereiro, maio, agosto e dezembro, de acordo com a Figura 2. Para cada um deles pode haver diferentes motivações para os aumentos ou diminuições na utilização dos serviços de saúde no Brasil:

- Janeiro é o mês em que se observa a menor utilização em relação aos outros meses. Um fator importante neste mês é o fato de ser o período de férias escolares e verão, quando existe uma grande procura por viagens e pouca procura de médicos;

- Fevereiro possui uma baixa utilização que pode refletir o "mês do carnaval" na maioria dos anos. O número de viagens também é alto, e o fato de existir praticamente uma semana inteira do mês em que não há procura por médicos, esse número de atendimentos cai. Um fato que evidencia a influência do carnaval sobre a uso dos serviços do SUS, é que no ano de 2011 em que o carnaval caiu em março, verificou-se que o valor não é tão baixo como nos outros anos (dado que fica ainda mais evidente quando observamos a Gráfico 2 de internações). $\mathrm{O}$ número de dias reduzido do mês de fevereiro também é uma forte hipótese causadora desse comportamento;

\footnotetext{
${ }^{4}$ Define-se por Atendimento Ambulatorial todo aquele realizado em âmbito do ambulatório, ou seja, fora do regime de internação, como consultas, exames, pequenas cirurgias, entre outros procedimentos.
} 
- Para o mês de maio não há uma explicação tão palpável como as anteriores para o aumento da utilização, no entanto é fácil notar esse comportamento nos 4 anos observados.

- Agosto é um mês em que notamos um aumento na frequência de utilização dos serviços de saúde. É um mês em que as temperaturas estão mais baixas, a presença de chuvas é menor, o que afeta a saúde dos cidadãos, como por exemplo, o aumento de doenças respiratórias nesse período devido à falta de umidade;

- Em dezembro verifica-se também uma queda no número de atendimentos que pode ser explicada pelo período de festas de fim de ano que afeta as duas últimas semanas do mês, onde existe também um aumento no número de pessoas viajando, e uma menor procura por exames e médicos;

Figura 3: Internações SUS no Brasil, de 2010 a 2013

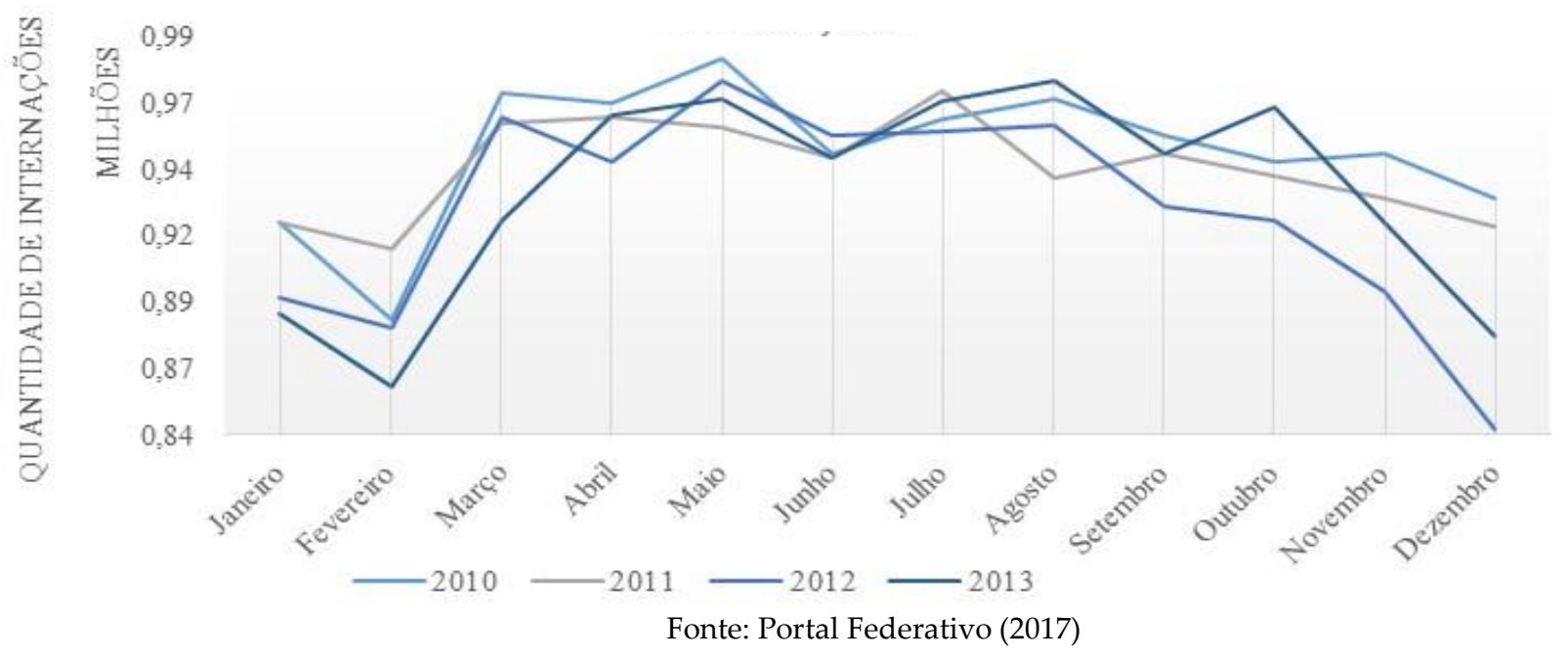

Quando se observa o número de Internações na Figura 3, verifica-se que os mesmos picos e pontos de queda nos meses citados anteriormente se mantém.

Além da questão da sazonalidade para a análise do sinistro por mês, também é importante que se leve em consideração uma sazonalidade dentro do mês. Por exemplo, quando os dias que antecedem o envio das contas possuem feriados, emendas de feriados e finais de semana, o valor do pagamento será bem reduzido já que a utilização dos serviços de saúde nessas datas tende a ser menor.

\section{METODOLOGIA}

Em relação ao pagamento de sinistros, as seguradoras, de modo geral, possuem dois tipos de pagamento: para os prestadores de sua rede referenciada/credenciada e diretamente para os beneficiários na forma de reembolso de um procedimento. Para os sinistros pagos na forma de reembolso, não é possível realizar um estudo para a estabilização dos valores, uma vez que não existe um cronograma de pagamento para tal.

Para a criação de um modelo de previsão de Sinistro pago por uma seguradora para os prestadores de serviços de sua rede referenciada em um determinado mês, utilizou-se a base de dados de uma seguradora tradicional no mercado.

O cronograma dessa seguradora possui as seguintes características:

- 4 datas de pagamento em cada mês;

- Períodos de recebimento pré-definidos com cerca de 5 dias úteis cada; 
- Mínimo de 10 dia úteis para a área de análise de contas, entre o recebimento das contas e o fechamento dos pagamentos; e

- Mínimo de 10 dias úteis para a área financeira organizar os pagamentos já fechados aos prestadores.

O objetivo do modelo é apurar qual o valor a ser pago por uma seguradora, contudo, este valor é impactado pelos serviços executados nos dias que antecedem o período de recebimento de contas a serem pagas pela seguradora (decorrentes dos serviços executados pelos prestadores de serviços) nesse período. Por exemplo, se considerarmos um intervalo de recebimento de contas do dia 10/03 a 14/03 de 2014, precisamos estudar quais os dias mais frequentes de execução de serviços, cujas contas serão enviadas à seguradora para serem pagas, que serão recebidos. Se os dias de ocorrência dos procedimentos mais observados for a própria semana teremos um sinistro com um determinado comportamento; porém, se os dias de execução com maior representatividade nas contas recebidas for a semana anterior, será possível verificar um valor de sinistro mais baixo, já que o feriado do carnaval foi justamente na semana anterior, o que com certeza causa uma redução na utilização dos planos de saúde.

Dessa forma, para a criação do modelo verificou-se o comportamento de cada execução (fatores de sazonalidade) e a relação entre os dias de execução e de recebimento de contas.

Para esta análise, utilizou-se uma base de dados contendo a data de execução do procedimento, a data de recebimento da conta, a data de pagamento efetivo da conta, o valor da conta e quantidade de vidas da carteira no período selecionado, que foi de 3 anos completos, com defasagem mínima de 4 meses $^{5}$. Portanto, os anos utilizados no modelo foram 2011, 2012 e 2013.

Primeiro, verificou-se qual o valor do sinistro PMPD para a amostra considerada. Sinistro PMPD, per member per day, é o total de sinistro ocorrido em um dia, dividido pelo número de beneficiários ativos ${ }^{6}$ daquele mesmo dia. A apuração desse sinistro sobre o número de ativos é de extrema importância, já que uma grande entrada ou saída de vidas pode afetar severamente o valor do sinistro pago. Para aplicar o sinistro PMPD, portanto, foi necessário fazer uma estimativa de vidas para o ano seguinte, a qual foi multiplicada pelo sinistro PMPD calculado para estimar o sinistro total pago.

O PMPD serviu de base para estabelecer médias de sinistro ocorrido para dias de características distintas. Para isso foi criado um 'calendário' em que constavam todos os dias dos anos observados e uma identificação para cada um deles, dia da semana (segundas, terças, quartas, quintas, sextas, sábados e domingos), feriados, emendas e vésperas de feriados ${ }^{7}$ (dependendo do dia da semana dos mesmos). Considerou-se então uma determinada média para cada particularidade, isto é, para cada situação específica que potencialmente afetará os fluxos de caixa e também de acordo com o mês. Ou seja, calculou-se uma matriz como a apresentada na Figura 4.

\footnotetext{
${ }^{5}$ A Defasagem é necessária pois, como demostraremos mais à frente iremos apurar o sinistro PMPD (per member per day) ocorrido, e como há um delay entre a ocorrência e o pagamento do sinistro, para o qual as seguradoras precisam, inclusive, constituir uma provisão de IBNP (Incurred but not paid), é preciso desconsiderar os meses mais recentes para que o sinistro esteja o mais maturado possível.

${ }^{6}$ É considerado Ativo todo aquele beneficiário que tem data de abertura de matrícula igual ou anterior à data mencionada, e data de exclusão igual ou posterior a mesma data.

${ }^{7}$ Consideradas Emendas apenas segundas e sextas e Vésperas apenas quando dias úteis.
} 
Figura 4: Exemplo de matriz de Sinistro PMPD

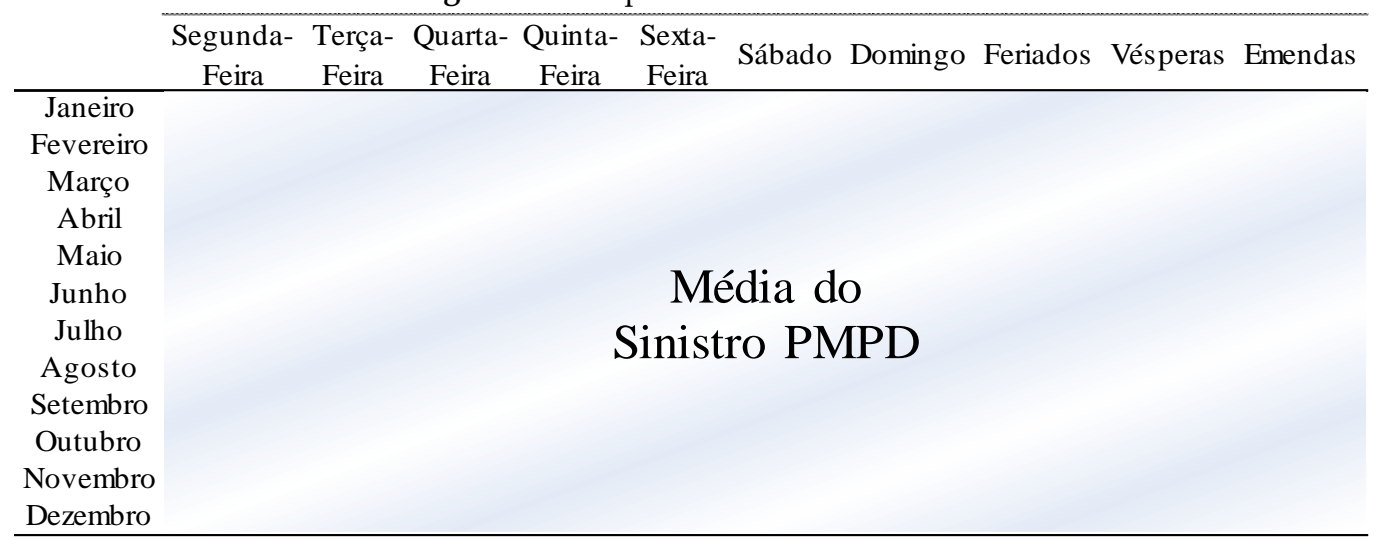

Foi importante observar também o desvio padrão para todas as segundas-feiras de cada mês, por exemplo, pois caso houvesse alto desvio padrão precisaríamos entender os motivos de tal para aplicarmos ao modelo.

Em uma segunda análise foi preciso entender o comportamento do recebimento de contas em comparação com as datas de execução das mesmas, ou seja, quanto tempo em média as contas demoram a ser recebidas para serem pagas pela seguradora. Porém, tem-se o conhecimento que uma mesma execução normalmente tem contas recebidas em mais de um período de execução.

Dessa maneira, foi mais eficaz realizar um estudo no qual pudemos entender o quanto de cada execução é recebido em cada um dos próximos períodos de recebimento de contas de acordo com o tempo decorrido entre as duas datas.

Para facilitar a aplicação dessa análise em conjunto com o Sinistro PMPD encontrado no primeiro estudo, devemos criar uma curva de recebimento de contas, que contém o percentual de cada execução em cada dia de recebimento, tal como a Figura 5 aponta ${ }^{8}$.

Figura 5: Exemplo de Curva de Recebimento

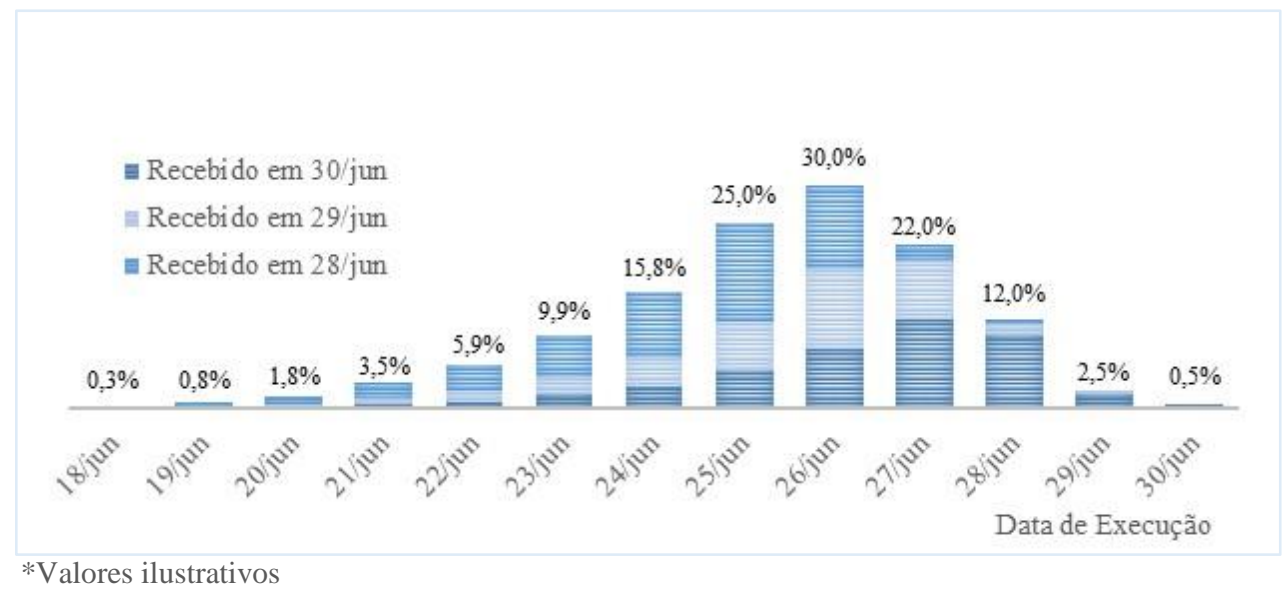

Podemos tirar as seguintes conclusões da Figura 5:

- $30 \%$ de todas as contas com execução em 26 de junho, forma recebidas em 28, 29 e 30 de junho;

- O recebimento do dia 30/jun contempla principalmente as ocorrências em 27/jun; o recebimento do dia 29/jun considera principalmente as ocorrências em 26/jun; e o recebimento do

\footnotetext{
${ }^{8}$ Figura com valores não reais.
} 
dia 28/jun, principalmente as ocorrências em 25/jun. Portanto, o quarto dia anterior à data de recebimento é o dia de execução do qual se recebe mais contas;

- Há diversas curvas de recebimento, uma para cada dia, de forma que se tirarmos a média de cada posição ${ }^{9}$ de execução é possível verificar a existência de uma única curva de recebimentos média.

Após as duas análises, preparamos um modelo para verificar quanto é recebido em cada semana de pagamento aplicando os percentuais da curva sobre os Sinistros PMPD, já que o valor a ser pago nada mais é do que o valor recebido nas semanas pré-determinadas, conforme apresentado na Figura 6. Com o modelo de estimativa de sinistro pago realizado, apenas alterou-se as datas de recebimento de contas para testar o valor do sinistro pago e torná-lo constante.

Figura 6: Esquema do modelo de estimativa

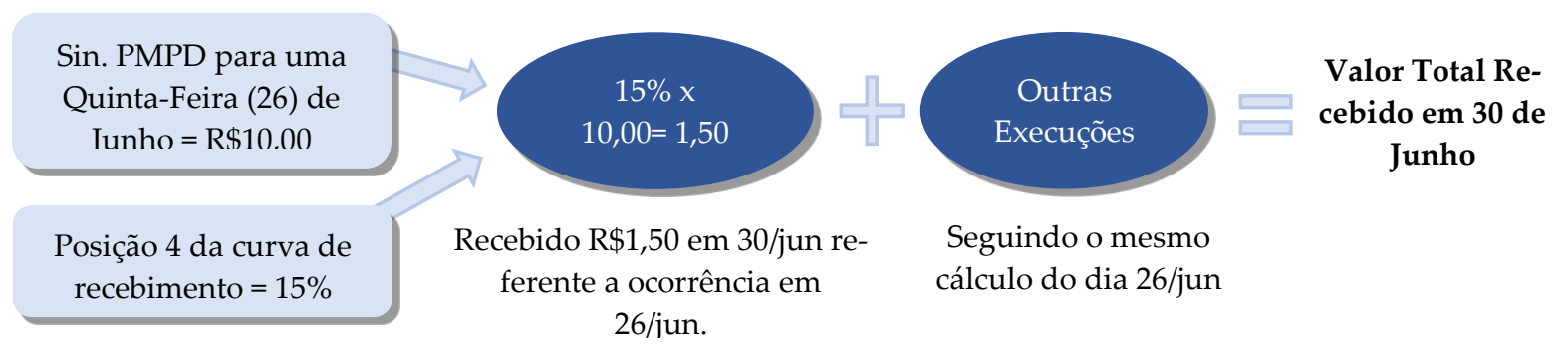

Foi necessário, posteriormente à criação do modelo, realizar um teste de consistência do mesmo, tentando estimar o sinistro pago em um ano do qual já possuímos todos os dados completos (2013, por exemplo), apenas para verificar a coerência dos valores estimados pelo modelo com a realidade.

\section{O MODELO}

\subsection{Matrizes de Execução}

No primeiro momento levou-se em consideração apenas a data de execução, o valor do sinistro, o calendário criado (com a identificação de cada dia do ano) e a base com o número de beneficiários ativos por dia. O cálculo do Sinistro PMPD médio nos ofereceu os resultados da Tabela 1.

O cálculo da média foi realizado por exemplo, tomando-se a razão entre o somatório de sinistros ocorridos nas segundas-feiras do mês de janeiro em cada ano, respectivamente, considerando como denominador dessa divisão o total de beneficiários ativos para a mesma base temporal, conforme denota a Equação 1 abaixo.

$$
\operatorname{SinPMPDS} S_{i}=\frac{\sum S S J}{\sum A S J}
$$

Em que: SinPMPDS refere-se à média de sinistro por membro $i$ por dia considerando-se somente as segundas-feiras do mês de janeiro. $\sum$ SSJ denota o somatório dos valores de sinistros ocorridos nas segundas-feiras de janeiro ao longo de diferentes períodos. E, por fim, $\sum$ ASJ representa o total de beneficiários ativos considerando-se a mesma periodicidade.

A partir do cômputo da média dos sinistros por membro levando-se em consideração os dias da semana, foi possível configurar a Tabela 1.

\footnotetext{
${ }^{9}$ Consideramos posição de execução o número de dias em relação a data de recebimento, ou seja, a posição 0 é a própria data de recebimento; a posição 1, a data anterior a data de recebimento, e assim por diante.
} 
Tabela 1: Sinistro PMPD - Dias Úteis, Sábados, Domingos

\begin{tabular}{|c|c|c|c|c|c|c|c|c|}
\hline \multirow[b]{2}{*}{ Mês } & \multicolumn{5}{|c|}{ Dias Úteis } & \multirow[b]{2}{*}{ Sáb } & \multirow[b]{2}{*}{ Dom } & \multirow{2}{*}{$\begin{array}{c}\text { Média de } \\
\text { Dias } \\
\text { Úteis }\end{array}$} \\
\hline & Segunda & Terça & Quarta & Quinta & Sexta & & & \\
\hline Jan & 8,50 & 8,82 & 8,72 & 8,41 & 7,65 & 4,78 & 2,69 & 8,44 \\
\hline Fev & 8,77 & 9,00 & 8,70 & 8,65 & 8,02 & 5,28 & 2,82 & 8,66 \\
\hline Mar & 9,06 & 9,07 & 8,75 & 8,98 & 8,47 & 5,31 & 3,22 & 8,87 \\
\hline Abr & 9,10 & 9,23 & 9,02 & 8,84 & 8,39 & 5,10 & 3,05 & 8,94 \\
\hline Mai & 9,00 & 8,95 & 8,90 & 8,86 & 8,34 & 5,20 & 3,08 & 8,82 \\
\hline Jun & 8,95 & 9,10 & 9,02 & 8,89 & 8,58 & 5,05 & 3,18 & 8,92 \\
\hline Jul & 9,13 & 9,52 & 9,43 & 8,99 & 8,71 & 5,40 & 3,10 & 9,17 \\
\hline Ago & 9,15 & 9,50 & 9,21 & 9,23 & 8,66 & 5,46 & 3,19 & 9,14 \\
\hline Set & 9,67 & 9,69 & 9,68 & 9,21 & 8,56 & 5,24 & 3,26 & 9,37 \\
\hline Out & 9,43 & 9,73 & 9,53 & 9,45 & 8,56 & 5,25 & 3,18 & 9,37 \\
\hline Nov & 9,96 & 9,81 & 9,51 & 9,42 & 8,78 & 5,17 & 3,27 & 9,49 \\
\hline \multirow[t]{2}{*}{ Dez } & 9,82 & 9,68 & 9,36 & 8,88 & 8,59 & 5,29 & 3,15 & 9,27 \\
\hline & & & & & & Média I & teis Ano & 8,97 \\
\hline
\end{tabular}

Observando a Tabela 1 é possível perceber que existem disparidades analisadas além das que haviam sido apresentadas na Figura 4. Isso acontece devido a novos pontos importantes que foram encontrados durante as análises.

a) Os feriados não possuem um padrão único, por isso fizemos uma análise para cada um dos feriados do ano, e suas respectivas emendas, conforme apresentado na Tabela 4.

b) As vésperas de feriados foram desconsideradas em virtude de não haver uma redução nos indicadores conforme se esperava (diferentemente das expectativas foi verificado uma pequena variação de comportamentos, por exemplo a véspera de Corpus Christi em 2011 teve uma pequena redução no valor do sinistro, já em 2012 o número foi maior do que os outros dias do mês).

c) A única véspera de feriado considerada é a sexta feira pré-carnaval, que possui uma redução significativa no valor do sinistro em relação as outras sextas do mês. (Vide Tabela 4)

d) Durante as análises dos feriados, percebemos que tanto o feriado de $1^{\circ}$ de Janeiro como de $1^{\circ}$ de Maio, tinham valores maiores do que os outros feriados. Após investigação sobre o motivo desse comportamento diferente para esses dias, pudemos notar na base de dados, não apenas para esses dois casos, mas para todos os $1^{\text {os }}$ dias de cada mês, esse comportamento de aumento do sinistro ocorrido.

Não existe, portanto, um claro motivo para que aconteça tal aumento no primeiro dia do mês. Uma hipótese é a de que os prestadores em casos de não preenchimento da data de ocorrência do procedimento, no momento do envio da conta (em que essa data é de preenchimento obrigatório), completam com o primeiro dia do mês. Isto é, sendo o campo data um item obrigatório de preenchimento nos formulários dos prestadores, pode ser que esse input esteja acontecendo de maneira protocolar, considerando-se uma data para a inserção, nesse caso o primeiro dia de cada mês.

Apesar do motivo desconhecido, sabemos que é um padrão o aumento da quantidade de contas com execução dia $1^{\circ}$, e portanto, tal padrão foi incluído no modelo, conforme demonstra-se na Tabela 2.

Tabela 2: Sinistro PMPD - Dias $1^{\mathrm{o}}$

\begin{tabular}{|c|c|c|c|c|c|c|}
\hline \multirow{3}{*}{$\frac{\text { Mês }}{\text { Jan }}$} & \multicolumn{6}{|c|}{ Dias $1^{0}$} \\
\hline & \multicolumn{2}{|c|}{2011} & \multicolumn{2}{|c|}{2012} & & \\
\hline & Sábado & 5,77 & Domingo & 5,81 & Terça & 7,35 \\
\hline
\end{tabular}




\begin{tabular}{ccccccc}
\hline Fev & Terça & 10,90 & Quarta & 12,10 & Sexta & 13,90 \\
Mar & Terça & 11,38 & Quinta & 12,26 & Sexta & 13,60 \\
Abr & Sexta & 10,48 & Domingo & 6,68 & Segunda & 14,89 \\
Mai & Domingo & 6,26 & Terça & 7,43 & Quarta & 10,11 \\
Jun & Quarta & 11,01 & Sexta & 12,63 & Sábado & 9,59 \\
Jul & Sexta & 11,81 & Domingo & 7,54 & Segunda & 14,84 \\
Ago & Segunda & 10,65 & Quarta & 13,25 & Quinta & 14,95 \\
Set & Quinta & 11,57 & Sábado & 9,80 & Domingo & 8,42 \\
Out & Sábado & 8,33 & Segunda & 13,92 & Terça & 15,93 \\
Nov & Terça & 11,75 & Quinta & 13,43 & Sexta & 15,09 \\
Dez & Quinta & 12,14 & Sábado & 9,82 & Domingo & 8,52 \\
\hline
\end{tabular}

A Tabela 3 demonstra-se o efeito de uma ponderação sobre os dias da semana considerandose as incidências verificadas a partir dos saldos médios. Isto é, notou-se que as distribuições não são uniformes considerando-se os dias da semana, portanto, foi incorporado aos saldos de PMDP o efeito das pesos observados para cada dia especificamente, criando assim reduções ou agravos sobre o Sinistro PMPD médio de Dias Úteis ${ }^{10}$.

Tabela 3: Fatores para cada dia da semana e finais de semana

\begin{tabular}{cccccccc}
\hline Mês & \multicolumn{3}{c}{ Dias Úteis } & Qúbado & Domingo \\
& Segunda & Terça & Quarta & Quinta & Sexta & Sáb \\
\hline Jan & $-5,2 \%$ & $-1,7 \%$ & $-2,8 \%$ & $-6,2 \%$ & $-14,7 \%$ & $-46,7 \%$ & $-70,1 \%$ \\
Fev & $-2,2 \%$ & $0,4 \%$ & $-3,0 \%$ & $-3,6 \%$ & $-10,6 \%$ & $-41,1 \%$ & $-68,5 \%$ \\
Mar & $0,9 \%$ & $1,1 \%$ & $-2,5 \%$ & $0,1 \%$ & $-5,6 \%$ & $-40,8 \%$ & $-64,1 \%$ \\
Abr & $1,5 \%$ & $2,8 \%$ & $0,5 \%$ & $-1,5 \%$ & $-6,5 \%$ & $-43,1 \%$ & $-66,0 \%$ \\
Mai & $0,3 \%$ & $-0,3 \%$ & $-0,8 \%$ & $-1,2 \%$ & $-7,1 \%$ & $-42,1 \%$ & $-65,6 \%$ \\
Jun & $-0,2 \%$ & $1,5 \%$ & $0,5 \%$ & $-0,9 \%$ & $-4,3 \%$ & $-43,8 \%$ & $-64,6 \%$ \\
Jul & $1,8 \%$ & $6,1 \%$ & $5,1 \%$ & $0,2 \%$ & $-3,0 \%$ & $-39,8 \%$ & $-65,4 \%$ \\
Ago & $2,0 \%$ & $5,8 \%$ & $2,6 \%$ & $2,8 \%$ & $-3,5 \%$ & $-39,1 \%$ & $-64,4 \%$ \\
Set & $7,7 \%$ & $8,0 \%$ & $7,9 \%$ & $2,7 \%$ & $-4,6 \%$ & $-41,5 \%$ & $-63,7 \%$ \\
Out & $5,1 \%$ & $8,4 \%$ & $6,2 \%$ & $5,4 \%$ & $-4,6 \%$ & $-41,5 \%$ & $-64,6 \%$ \\
Nov & $11,0 \%$ & $9,3 \%$ & $6,0 \%$ & $5,0 \%$ & $-2,1 \%$ & $-42,4 \%$ & $-63,6 \%$ \\
Dez & $9,4 \%$ & $7,9 \%$ & $4,3 \%$ & $-1,0 \%$ & $-4,3 \%$ & $-41,0 \%$ & $-64,9 \%$ \\
\hline
\end{tabular}

Para o cálculo dos agravos e redutores para dias $1^{0}$ e Feriados, Emendas e Véspera, primeiro foi preciso "desazonalizar", isto é, eliminar tendências que se repetem com certa periodicidade nas séries, a fim de que se tornem comparáveis o dia de acordo com a Tabela 4. Isso foi feito, pois o modelo aplica esses fatores sobre o Sinistro PMPD já com os fatores da Tabela 3. Além disso, no caso dos feriados, quando calculamos os fatores de redução dessa forma (retirando os efeitos do dia da semana em que o mesmo cai) podemos aplicar esse fator sobre o feriado no ano seguinte em que esse feriado cairá, com certeza, em outro dia da semana.

\footnotetext{
${ }^{10}$ Considerados nesse Sinistro PMPD Médio apenas dias úteis, exceto dia $1^{\circ}$ de cada mês, Emendas e Vésperas de feriados.
} 
Tabela 4: Redutores para Feriados, Emendas e Véspera

\begin{tabular}{lcccc}
\hline & \multicolumn{2}{c}{ Feriados } & \multicolumn{2}{c}{ Emendas } \\
& Segunda à Sexta & Sábado & Domingo & Dias Úteis \\
\hline Carnaval & $-69,3 \%$ & - & - & - \\
Natal & $-75,1 \%$ & $-55,7 \%$ & $-36,2 \%$ & - \\
Quarta de Cinzas & $-29,6 \%$ & - & - & - \\
Vésp. De Natal & $-71,9 \%$ & $-56,5 \%$ & $-36,2 \%$ & - \\
Vésp. De Ano Novo & $-69,7 \%$ & $-54,9 \%$ & $-36,2 \%$ & - \\
Municipal SP & $-17,6 \%$ & $-6,1 \%$ & $0,0 \%$ & $-11,5 \%$ \\
Estadual SP & $-34,7 \%$ & $-12,1 \%$ & $0,0 \%$ & $-19,2 \%$ \\
Estadual SP e RJ & $-28,7 \%$ & $-12,1 \%$ & $0,0 \%$ & $-10,3 \%$ \\
Sexta Pré-Carnaval & $-13,5 \%$ & - & - & - \\
Sábado Pré-Carnaval & - & $-18,7 \%$ & - & - \\
Domingo Pré-Carnaval & - & - & $-17,6 \%$ & - \\
Qui e Sex Pós-Carnaval & $-3,0 \%$ & - & - & - \\
Outros & $-57,2 \%$ & $-19,1 \%$ & $-2,6 \%$ & $-27,1 \%$ \\
\hline
\end{tabular}

No cálculo do agravo para dia $1^{\circ}$ (Tabela 5) foi considerado qual o dia da semana de cada dia $1^{\circ}$, pois há diferenças no percentual de agravo, e por exemplo para o caso de ser um feriado em dia de semana (segunda a sexta) há uma redução do valor médio e não um agravo.

\begin{tabular}{cc} 
Tabela 5: Fatores de Agravo para dia $1^{\circ}$ \\
\hline $\begin{array}{c}\text { Dia } \mathbf{1}^{\mathbf{0}} \\
\text { Dia da Semana }\end{array}$ & Agravo \\
\hline Domingo & $128,2 \%$ \\
Segunda & $36,5 \%$ \\
Terça & $37,3 \%$ \\
Quarta & $32,2 \%$ \\
Quinta & $42,9 \%$ \\
Sexta & $40,4 \%$ \\
Sábado & $80,6 \%$ \\
Feriado (Segunda a Sexta) & $-19,0 \%$ \\
\hline
\end{tabular}

\subsection{Curvas de Execução versus Recebimento}

Para a criação das curvas de Execução versus Recebimento foi utilizada uma base com: data de execução, data de recebimento da conta, e o valor do sinistro. Montamos uma Matriz com o montante de sinistro recebido em cada dia por dia de execução conforme Tabela $6^{11}$.

Note que os dias 12/01/13 e 13/01/13, conforme demonstra a Tabela 6, por serem sábado e domingo, respectivamente, possuem um montante recebido bem menor do que nos demais dias, e devido a insignificância percentual desses valores, ignorou-se os recebimentos em finais de semana e feriados para o cálculo da curva média e do Desvio Padrão.

\footnotetext{
${ }^{11}$ As Tabelas 6, 7 e 8 apresentadas não estão completas, pois as mesmas são abertas por dia para 3 anos, e portanto, são muito grandes.
} 
Tabela 6: Montante de sinistro recebido por dia de execução

\begin{tabular}{|c|c|c|c|c|c|c|c|c|c|}
\hline \multirow{2}{*}{$\begin{array}{c}\text { Data da } \\
\text { Execução }\end{array}$} & \multicolumn{8}{|c|}{ Data de Recebimento } & \multirow{2}{*}{ Total } \\
\hline & $\ldots$ & $10 / 01 / 2013$ & $11 / 01 / 2013$ & $12 / 01 / 2013$ & $13 / 01 / 2013$ & $14 / 01 / 2013$ & $15 / 01 / 2013$ & $\ldots$ & \\
\hline $15 / 01 / 2013$ & $\ldots$ & - & - & - & - & - & $50.814,26$ & $\ldots$ & 9.450.005, \\
\hline $14 / 01 / 2013$ & $\ldots$ & - & - & - & - & $109.998,63$ & $109.020,48$ & $\ldots$ & 8.954 .5494 \\
\hline $13 / 01 / 2013$ & $\ldots$ & - & - & - & $7.073,62$ & $1.594,41$ & $24.795,66$ & $\ldots$ & $2.976 .425,59$ \\
\hline $12 / 01 / 2013$ & $\ldots$ & - & - & $3.683,47$ & 518,52 & $12.796,51$ & $96.251,95$ & $\ldots$ & $4.901 .822,37$ \\
\hline $11 / 01 / 2013$ & $\ldots$ & - & $56.754,64$ & $4.964,53$ & $1.360,38$ & $124.197,03$ & $275.353,42$ & $\ldots$ & $8.343 .996,02$ \\
\hline $10 / 01 / 2013$ & $\ldots$ & $139.560,80$ & $166.855,25$ & $4.728,50$ & 768,63 & $198.735,00$ & $391.334,19$ & $\ldots$ & $9.233 .761,20$ \\
\hline 09/01/2013 & $\ldots$ & $297.111,75$ & $475.263,93$ & $21.244,40$ & 793,33 & $198.106,35$ & $420.906,54$ & $\ldots$ & $9.411 .132,04$ \\
\hline 08/01/2013 & $\ldots$ & $542.651,93$ & $497.949,96$ & $15.331,91$ & $1.354,77$ & $233.145,03$ & $406.460,30$ & $\ldots$ & $8.824 .473,44$ \\
\hline
\end{tabular}

Calculou-se a proporção de cada execução que é recebida em cada data de recebimento (conforme explicado na metodologia e apresentado na Figura 5). Além do cálculo da proporção, organizou-se a matriz em lags ${ }^{12}$ de execução ao invés das datas, de forma que o lag 0 representa que a data de execução é igual a data recebimento; o lag 1 representa que a data de execução é um dia antes da data de recebimento. Ou seja:

$$
D E X_{\operatorname{lag} x}=D R-\operatorname{lag} x
$$

Em que: DEX $X_{\text {lagx }}$ representa a data de execução respectivamente defasada pelos atrasos medidos em dias. DR refere-se a data do recebimento. E, por fim, lag $x$ refere-se aos atrasos metrificados em dias.

Posteriormente ao cálculo da data de execução com base na Equação 2, foi elaborada a Tabela 7 em que se apresenta a proporção de sinistros por dia vis-à-vis os atrasos (lags) de comunicação.

Tabela 7: Proporção de sinistro recebido por dia de execução e curva média

\begin{tabular}{|c|c|c|c|c|c|c|c|c|c|c|}
\hline \multirow{2}{*}{ Lag } & \multicolumn{8}{|c|}{ Data de Recebimento } & \multirow{2}{*}{$\begin{array}{l}\text { Curva } \\
\text { Média }\end{array}$} & \multirow{2}{*}{$\begin{array}{l}\text { Desvio } \\
\text { Padrão }\end{array}$} \\
\hline & $\ldots$ & $10 / 01 / 2013$ & $11 / 01 / 2013$ & $12 / 01 / 2013$ & $13 / 01 / 2013$ & $14 / 01 / 2013$ & $15 / 01 / 2013$ & $\ldots$ & & \\
\hline 0 & $\ldots$ & $1,5 \%$ & $0,7 \%$ & $0,1 \%$ & $0,2 \%$ & $1,2 \%$ & $0,5 \%$ & $\ldots$ & $0,6 \%$ & $0,33 \%$ \\
\hline 1 & $\ldots$ & $3,2 \%$ & $1,8 \%$ & $0,1 \%$ & $0,0 \%$ & $0,1 \%$ & $1,2 \%$ & $\ldots$ & $2,0 \%$ & $1,11 \%$ \\
\hline 2 & $\ldots$ & $6,1 \%$ & $5,1 \%$ & $0,1 \%$ & $0,0 \%$ & $0,3 \%$ & $0,8 \%$ & $\ldots$ & $3,2 \%$ & $1,55 \%$ \\
\hline 3 & $\ldots$ & $6,7 \%$ & $5,6 \%$ & $0,2 \%$ & $0,0 \%$ & $1,5 \%$ & $2,0 \%$ & $\ldots$ & $3,4 \%$ & $1,92 \%$ \\
\hline 4 & $\ldots$ & $2,7 \%$ & $5,4 \%$ & $0,2 \%$ & $0,0 \%$ & $2,2 \%$ & $3,3 \%$ & $\ldots$ & $3,7 \%$ & $1,81 \%$ \\
\hline 5 & $\ldots$ & $7,5 \%$ & $3,6 \%$ & $0,2 \%$ & $0,0 \%$ & $2,1 \%$ & $4,2 \%$ & $\ldots$ & $4,4 \%$ & $2,04 \%$ \\
\hline 6 & $\ldots$ & $8,7 \%$ & $6,3 \%$ & $0,1 \%$ & $0,0 \%$ & $2,6 \%$ & $4,5 \%$ & $\ldots$ & $5,0 \%$ & $2,34 \%$ \\
\hline 7 & $\ldots$ & $7,1 \%$ & $6,5 \%$ & $0,2 \%$ & $0,0 \%$ & $2,7 \%$ & $4,6 \%$ & $\ldots$ & $5,3 \%$ & $2,48 \%$ \\
\hline$\ldots$ & & & & & & & & & $\ldots$ & $\ldots$ \\
\hline
\end{tabular}

Exemplificando, na Tabela 7, verifica-se 3,2\% na coluna da data 10/01/2013 e linha do lag 1. Isso significa que, 3,2\% do sinistro total ocorrido em 09/01 (dia 10 - lag 1) foi recebido no dia 10. Observando na Tabela 6, vemos que 3,2\% $=297.111,75 / 9.411 .132,04$ (sinistro recebido em 10/01 relativo ao sinistro ocorrido em 09/01, sobre sinistro total ocorrido em 09/01).

Analisando-se detalhadamente o montante de recebimento, nota-se uma variação que modifica o total de sinistros recebidos em cada dia.

Conforme apresentado no exemplo da Tabela 8 a seguir, o qual considera o cronograma de junho de 2013, cujo período de recebimento foi de 17/06/13 a 21/06/13. Nota-se que o montante de sinistro recebidos no penúltimo (20) e último (21) dias do cronograma é nitidamente maior do que nos dias anteriores. Observe que o mesmo padrão de repete para a semana seguinte (24/06 a 28/06).

\footnotetext{
${ }^{12}$ lag, em português significa atraso, demora, retardo, defasagem. Ou seja, nesse caso significa a demora, ou o período (em dias) entre recebimento e execução.
} 
Tabela 8: Montante recebido em cada dia do mês

\begin{tabular}{ccc}
\hline & $\begin{array}{c}\text { Recebimento } \\
\text { Posição }\end{array}$ & Montante \\
\hline Ante-2 dia & $17 / 06 / 2013$ & $5.764 .119,75$ \\
Ante-1 dia & $18 / 06 / 2013$ & $8.583 .525,75$ \\
Antepenúltimo dia & $19 / 06 / 2013$ & $11.854 .942,94$ \\
Penúltimo dia & $20 / 06 / 2013$ & $16.620 .337,57$ \\
Último dia & $21 / 06 / 2013$ & $13.361 .421,25$ \\
Ante-2 dia & $24 / 06 / 2013$ & $10.793 .092,34$ \\
Ante-1 dia & $25 / 06 / 2013$ & $8.399 .350,97$ \\
Antepenúltimo dia & $26 / 06 / 2013$ & $11.530 .459,70$ \\
Penúltimo dia & $27 / 06 / 2013$ & $20.153 .764,68$ \\
Último dia & $28 / 06 / 2013$ & $19.781 .700,01$ \\
\hline
\end{tabular}

Diferentemente dos maiores valores de sinistro observados com ocorrência no dia $1^{\mathrm{o}}$ de cada mês, que não possuem claros motivos para acontecer, para essa característica existe uma explicação presumível. O controle de contas dos prestadores faz com que o envio de contas no final de cada cronograma seja maior para que a quantia a ser paga pelas operadoras seja maior também. Ou seja, em termos bem práticos, à medida que vai chegando o fechamento de um cronograma o pessoal de envio de contas dos prestadores agiliza o envio para conseguir que um valor maior seja pago na próxima data, pois caso não seja possível enviar a conta até o fechamento desse cronograma, o valor será pago apenas na data de pagamento seguinte.

Tabela 9: Curvas média por posição de recebimento

\begin{tabular}{c|cc|cc|cc|cc}
\hline \multirow{2}{*}{$\begin{array}{c}\text { Lag de } \\
\text { Execução }\end{array}$} & \multicolumn{2}{|c|}{ Último } & \multicolumn{2}{|c|}{ Penúltimo } & \multicolumn{2}{|c|}{ Antepenúltimo } & \multicolumn{2}{c}{ Ante-1 } \\
\cline { 2 - 8 } & Média & $\begin{array}{c}\text { Desv. } \\
\text { Pad. }\end{array}$ & Média & $\begin{array}{c}\text { Desv. } \\
\text { Pad. }\end{array}$ & Média & $\begin{array}{c}\text { Desv. } \\
\text { Pad. }\end{array}$ & Média & $\begin{array}{c}\text { Desv. } \\
\text { Pad. }\end{array}$ \\
\hline 0 & $0,54 \%$ & $0,30 \%$ & $0,96 \%$ & $0,32 \%$ & $0,55 \%$ & $0,25 \%$ & $0,48 \%$ & $0,21 \%$ \\
1 & $2,14 \%$ & $1,02 \%$ & $3,29 \%$ & $1,03 \%$ & $1,86 \%$ & $0,76 \%$ & $1,33 \%$ & $0,66 \%$ \\
2 & $3,62 \%$ & $1,33 \%$ & $5,05 \%$ & $1,35 \%$ & $3,07 \%$ & $1,11 \%$ & $2,10 \%$ & $0,71 \%$ \\
3 & $4,06 \%$ & $1,46 \%$ & $5,59 \%$ & $1,78 \%$ & $3,02 \%$ & $1,26 \%$ & $2,27 \%$ & $1,01 \%$ \\
4 & $4,68 \%$ & $1,41 \%$ & $5,97 \%$ & $1,59 \%$ & $3,42 \%$ & $1,07 \%$ & $2,66 \%$ & $0,91 \%$ \\
\hline
\end{tabular}

Analisando, portanto, esse padrão, a curva média se dividiu em curvas diferentes de acordo com a "posição" do dia de recebimento dentro do cronograma, se último, penúltimo, antepenúltimo e assim por diante. Identificou-se na Tabela 7 as posições de recebimento e retirou-se a média para cada uma delas. Dessa forma, criou-se a Tabela 9. Note que o desvio padrão encontrado para cada curva é menor do que o encontrado na Tabela 7. Enquanto que o maior Desvio Padrão nessa Matriz não chega aos $2 \%$, no cálculo anterior atingia quase $2,5 \%$. Os desvios ainda são altos, porém uma redução de mais de 0,5 ponto percentual pode trazer grandes melhorias a eficácia do modelo.

\subsection{Estimativa do Sinistro Pago}

Para estimar os valores dos sinistros pagos, aplicou-se os valores calculados para cada uma das matrizes finais, conforme a Figura 7 a seguir, visando estimar o sinistro recebido - referente a um dia de execução - em cada dia, e, dessa maneira calcular o sinistro pago em determinada data (a partir da soma de um período de recebimento e multiplicando pelo número de vidas), conforme Equação 3.

$$
\begin{aligned}
\text { Sin }_{\text {receb. }}= & \operatorname{Sin} P M P D \times\left(1+\text { Parâmetro }_{\text {tabela } 3}\right) \times\left(1+\text { Parâmetro }_{\text {tabela } 4}\right) \times \\
& \left(1+\text { Parâmetro }_{\text {tabela }}^{*}\right) \times \text { Parâmetro }_{\text {tabela }} 9
\end{aligned}
$$


A partir do modelo proposto na Equação 3, foi realizada uma simulação visando estabelecer o valor do sinistro recebido conforme pode ser observado na Figura 7. Cumpre destacar que os parâmetros foram obtidos por meio das análises realizadas nas tabelas precedentes.

Figura 7: Modelo de estimativa de sinistro pago

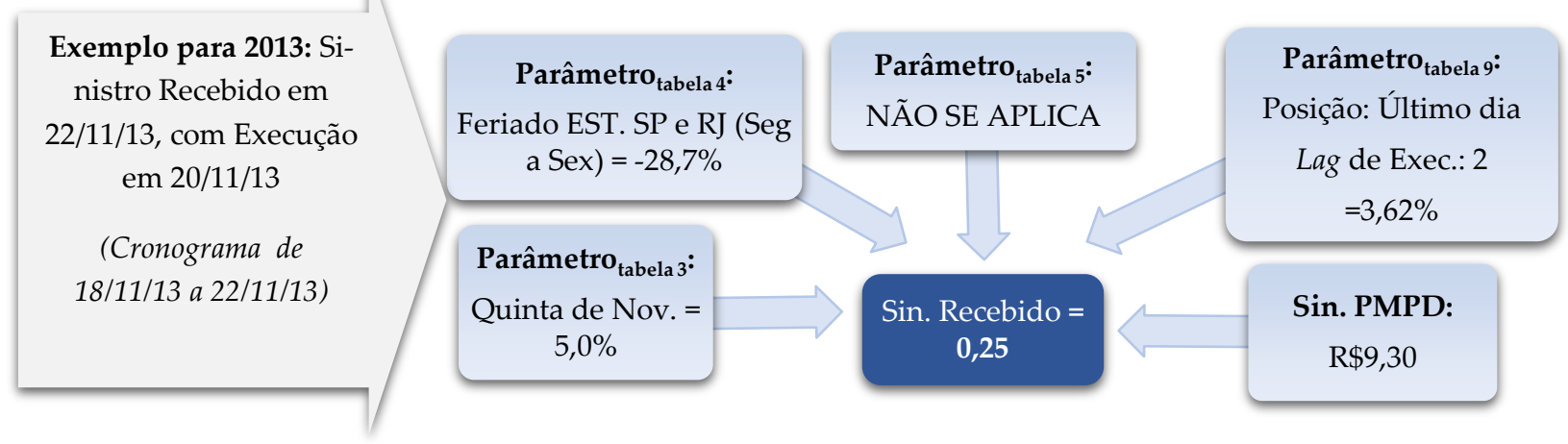

Considere que o sinistro per capita e por dia útil para o ano de 2013 é estimado em R\$9,30. Pelo cálculo do Parâmetrotabela 3, sabemos que o valor do sinistro PMPD médio de dias úteis para uma quinta-feira de novembro (dia de execução 20/11/13), deve ser agravado em 5,0\%. Porém, esse valor deve ser também reduzido em 28,7\% (observando o Parâmetrotabela 4) já que o dia 20/11/13 é um feriado. Em relação ao recebimento, sabemos que a execução de 20/11/13 é o lag 2 na curva de recebimento do dia 22/11/13, que é o último dia de recebimento do período de 18 a 22/11/13 no cronograma. Pelo Parâmetrotabela 9 podemos inferir que 3,62\% da soma dos sinistros ocorridos no dia 20/11/13 será recebido em 22/11/13. O Parâmetrotabela 5 não se aplica já que não se trata de $1^{\circ}$ dia do mês.

Aplicando todas essas matrizes conforme a expressão apresentada na Figura 7 chegou-se ao valor de 0,25 que representa o montante de contas recebido no dia 22 de novembro relativo ao sinistro ocorrido em 20 de novembro de 2013, para uma pessoa da carteira de beneficiários. Ou seja, para calcular o sinistro total recebido em um dia, é preciso aplicar a mesma fórmula para os outros dias de execução que compõe esse recebimento $(22,21,19,18,17 /$ nov, e assim por diante) e multiplicar o sinistro ocorrido em cada dia pela quantidade de beneficiários ativos na carteira no dia da ocorrência do sinistro.

Para análise do modelo proposto para estimativa dos valores de sinistros a serem pagos, nas respectivas datas definidas no cronograma de pagamentos da seguradora, foi feito um análise prospectiva, apresentada a seguir.

\subsection{Teste de Consistência e Novos Períodos de Recebimento}

Foi realizado um teste de consistência para verificar a aderência do modelo para o ano de 2014. No entanto, à época eram conhecidos os valores reais até outubro de 2014. Assim, a partir do modelo proposto, estimou-se os valores de sinistros a serem pagos nos meses de janeiro a outubro de 2014 e comparou os valores estimados com os valores reais. O resultado da estimativa de sinistros pagos, utilizando as datas do cronograma real que estava vigente em 2014, está representado na Tabela 10. 
Tabela 10: Teste de Consistência para 2014

\begin{tabular}{cccc}
\hline \multirow{2}{*}{ Mês } & Sin. Estimado & Sin. Real & Diferença \\
\hline Jan & $319.594 .997,24$ & $313.208 .512,54$ & $2,0 \%$ \\
Fev & $343.372 .037,31$ & $294.038 .432,75$ & $16,8 \%$ \\
Mar & $306.799 .620,10$ & $297.119 .750,34$ & $3,3 \%$ \\
Abr & $311.923 .742,20$ & $335.242 .121,74$ & $-7,0 \%$ \\
Mai & $341.299 .353,03$ & $313.988 .918,02$ & $8,7 \%$ \\
Jun & $294.025 .812,00$ & $344.870 .042,32$ & $-14,7 \%$ \\
Jul & $289.900 .188,50$ & $313.886 .378,34$ & $-7,6 \%$ \\
Ago & $359.888 .631,04$ & $322.345 .182,06$ & $11,6 \%$ \\
Set & $375.448 .601,12$ & $342.749 .377,62$ & $9,5 \%$ \\
Out & $316.033 .256,46$ & $315.374 .111,12$ & $0,2 \%$
\end{tabular}

Como é possível notar apesar de na maioria dos meses não ter ultrapassado $10 \%$ (em módulo), a aderência do modelo foi baixa para os meses de Fevereiro, Junho e Agosto, onde a diferença entre o valor de sinistro real e estimado superou $10 \%$. Entretanto é importante destacar que a média e a mediana da diferença entre o estimado e o realizado considerando-se os meses analisados de 2014 foram respectivamente $2,31 \%$ e 3,30\%. Naturalmente em virtude de potenciais efeitos sazonais esses valores não se mantém constantes ou próximos durante o passar dos meses, implicando em um elevado desvio padrão o qual para o período avaliado ficou na ordem de 10,42\%, contido em um intervalo de $-14,70 \%$ e 16,80\%, respectivamente limites mínimo e máximo.

É fundamental destacar que embora haja elevada variação entre os resultados encontrados de um mês para outro, em linhas gerais o modelo proposto possui uma aderência interessante, sobretudo, quando considerada a elevada quantidade de elementos que podem afetar a relação de pagamentos realizados comparativamente aos orçados. Adicionalmente, o desenvolvimento de um modelo para tal previsão não é uma atividade determinística e terminal, isto é, os modelos precisam ser ajustados periodicamente a fim de incorporarem novos elementos preditivos que possam melhorar as predições buscados pela modelagem proposta.

\section{Considerações Finais}

Este estudo teve como objetivo criar um modelo de estimativa de pagamentos mensais de uma operadora de planos de saúde para os prestadores de sua rede, de forma que, ao antecipar o conhecimento desses valores, seja possível para a empresa uma melhor gestão financeira.

De acordo com as análises, verificou-se que o montante dos pagamentos de sinistros é influenciado de forma mais relevante pelo mês, pelos dias da semana (dias úteis, sábados e domingos) e pela existência de feriados no período em questão.

A partir do Modelo criado para estimar os pagamentos mensais de uma operadora de planos de saúde para os prestadores de sua rede, verificou-se que a aderência do Modelo foi boa para 7 dos 10 meses analisados. Comparando os valores estimados a partir do Modelo com os valores reais, verifica-se que para 7 meses o erro em módulo foi inferior a 10\%. No entanto, para os 3 meses restantes verificou-se um erro mais significativo. Isso acontece devido à grande vulnerabilidade dos dados em questões que refletem comportamentos humanos e podem ter diversos outros fatores correlacionados, como por exemplo:

- O envio de contas pelos prestadores depende muito da "pretensão" daqueles que as enviam;

- A temperatura e condições climáticas em geral interferem também na frequência de utilização; 
- A sazonalidade da execução em geral depende muito da utilização dos planos de saúde pela população;

- O recebimento de contas em finais de semana e feriados pode ter uma influência maior do que a calculada, e o fato de não considerarmos pode ter prejudicado o modelo.

Assim, estes pontos (e outros) fazem com que a variação dos valores das matrizes calculadas seja grande de um ano para o outro, o que afeta o modelo de forma negativa já que toda a estimativa futura está baseada em comportamentos do passado.

Apesar das limitações apresentadas pelo modelo, é importante destacar que, em linhas gerais, o modelo proposto possui uma aderência interessante, sobretudo, quando considerada a elevada quantidade de elementos que podem afetar a relação de pagamentos realizados comparativamente aos orçados. Adicionalmente, o desenvolvimento de uma ferramenta que possibilite estimar os fluxos de caixa futuros faz com que seja possível incrementar os procedimentos de gestão de recursos financeiros das operadoras de planos de saúde e, por conseguinte, incorrer em melhores resultados financeiros.

Dessa maneira, para que se tenha resultados melhores, o Modelo de estimativa de pagamentos em uma operadora precisa incorporar outros fatores que possam influenciar a ocorrência e o recebimento de sinistros como, por exemplo, o perfil das carteiras das seguradoras e a região. Apesar disso, é possível utilizar o Modelo para que se tenha uma estimativa de pagamentos a serem realizados durante o ano.

Para futuras pesquisas, além de aprimorar o presente Modelo, sugere-se uma análise da variabilidade dos pagamentos feitos nos períodos, uma vez que a gestão financeira da empresa seria melhor se os pagamentos fossem constantes no decorrer do ano, de forma a alocar melhor os prêmios recebidos, uma vez que o prêmio não sofre tais alterações sazonais, apenas são reajustados anualmente. Uma das alternativas para estabilizar os valores de pagamentos é ajustar o cronograma de pagamento aos prestadores. Ajustando-se as datas desses cronogramas, como por exemplo, diminuindo o intervalo de recebimento de contas para o pagamento em um determinado mês cujos valores costumam ser mais altos, seria possível reduzir o pagamento desse mês e passá-lo para o próximo mês em que o pagamento costuma ser menor.

\section{REFERÊNCIAS}

Allen, F; Brealey, R. \& Myers, S. Princípios de Finanças Corporativas. 8ª ed. São Paulo: McGrawHill, 2008.

Assaf Neto, A., \& Silva, C. A. T. (2002). Administração do capital de giro. 3. ed. São Paulo: Atlas.

Brasil. Agência Nacional de Saúde Suplementar. Resolução Normativa no 71, de 2004. “Estabelece os requisitos dos instrumentos jurídicos a serem firmados entre as operadoras de planos privados de assistência à saúde ou seguradoras especializadas em saúde e profissionais de saúde ou pessoas jurídicas que prestam serviços em consultórios".

Brasil. Lei 9.656. “Dispõe sobre os planos e seguros privados de assistência à saúde”. Brasília, 1998.

Brasil. Lei 11.638. “Altera e revoga dispositivos da Lei no 6.404, de 15 de dezembro de 1976, e da Lei no 6.385, de 7 de dezembro de 1976, e estende às sociedades de grande porte disposições relativas à elaboração e divulgação de demonstrações financeiras". Brasília, 2007.

Campello, R. C. (2005). Análise multicritério aplicada à classificação da solvência de operadoras de assistência à saúde. Dissertação de mestrado, Universidade Federal Fluminense (UFF). Niterói, RJ. 
DATASUS. Informações de Saúde (TABNET). Assistência à Saúde. 2014. <http://www2.datasus.gov.br/DATASUS/index.php?area=0202>.

Frezzati, F. (2006). Gestão do fluxo de caixa diário: como dispor de um instrumento fundamental para o gerenciamento do negócio. São Paulo: Atlas.

Galiza, Francisco. Seguradoras: motivos estratégicos na definição de um nível ótimo de liquidez. FGV. 2001. <http://www.ratingdeseguros.com.br/pdfs/artigo110.pdf>.

Knyazeva, E., Yuzvovich, L., Smordina, E., Fomenko, V., \& Katochikov, V. (2016). Cash flow management at the insurance company aimed at provision of financial stability. American Journal of Applied Sciences, 13(6), 794-803.

Mano, C. C. A.; Ferreira, P. P. Aspectos Atuariais e Contábeis das Provisões Técnicas. $1^{\underline{a}}$ ed. Funenseg, 2009.

Martins, E., Gelbecke, E. R., Santos, A., \& Iudícibus, S. (2013). Manual de Contabilidade Societária: Aplicável a todas as sociedades de acordo com as normas internacionais e do CPC. Segunda Edição. São Paulo: Atlas.

Melhoramentos. Minidicionário da Língua Portuguesa. Editora Melhoramentos. 20ae ed. 2000.

Oliveira, R. M. S.; Lima, C. R. M. Prestadores de Serviços no Setor de Saúde Suplementar no Brasil. Rio de Janeiro: ANS, 2003.

Portal de Contabilidade. DFC - Demonstrações de Fluxo de Caixa. 2014. <http://www.portaldecontabilidade.com.br/tematicas/ademonstracaodosfluxos.htm>.

Salles, E., \& Santos, L. M. (2004). A evolução da solvência, das provisões técnicas e da técnica atuarial: uma visão técnico-jurídica. Caderno de Seguros da Funenseg, 123 (24), 27-34.

Tempo Saúde. Manual de Orientações Técnicas e Administrativas ao Referenciado. 2011. $<$ http://www.temposaude.com.br/mac/upload/arquivo/documentos/temposaude/manual_prestador.pdf $>$.

UNIMED. Plano. Definições e Terminologia. 2009. <http://www.unimed.coop.br/pct/index. jsp?cd_canal $=54353 \&$ cd_secao $=55824>$.

Westenberger, R. (1995). Solvência de Seguradoras. Relatório Coppead № 297. Rio de Janeiro, RJ, Brasil. Universidade Federal do Rio de Janeiro. 